\title{
Systematic trial of pacing to prevent atrial fibrillation (STOP-AF)
}

The association of tachycardias with bradycardias was recognised almost 90 years ago, ${ }^{1}$ and has since been termed the brady-tachy syndrome, which in turn is one part of the sick sinus syndrome. Sinus node dysfunction is a major component of this syndrome, although the mechanism by which it is associated with either atrial arrhythmias or supraventricular tachycardia is not clear. Adenosine has been proposed as a common mediator. ${ }^{2}$

In the past, patients with sick sinus syndrome have often received pacemakers either to prevent spontaneously occurring pauses, or to allow the prescription of antiarrhythmic drugs, given to reduce the frequency of or to prevent atrial arrhythmias, but which may have the unwanted side effect of exacerbating bradycardia. Both single chamber ventricular (VVI) and atrial (AAI) pacemakers have been used, as have dual chamber (DDD) pacemakers.

Patients with any manifestation of the sick sinus syndrome are at increased risk of atrial arrhythmias. ${ }^{3}$ There is also a potential additional risk of atrial fibrillation caused by ventricular pacing itself, with overt or concealed conduction to the atrium via the $\mathrm{AV}$ node. ${ }^{4}$ This additional risk of atrial fibrillation has been demonstrated in a retrospective study of patients with AV block $(4.0 \%$ for VVI $v$ $0.7 \%$ DDD $)^{5}$ and appears to add risk over and above any propensity of patients with sick sinus syndrome to develop atrial fibrillation.

Retrospective studies suggest that atrial pacing has benefits in terms of both morbidity and mortality. ${ }^{67}$ Rosenqvist et $a l^{6}$ compared VVI and AAI pacing in two groups of patients with sinus node disease. Atrial fibrillation and congestive heart failure were both more common in those treated with VVI pacing, with chronic atrial fibrillation developing in $30 \%$ compared with $4 \%$ of those paced AAI at two years, ${ }^{6}$ and in $47 \%$ and $7 \%$, respectively, at four years. ${ }^{7}$ Longer follow up demonstrated a difference in survival between the two groups $(23 \% v 8 \%)$, the excess mortality in the VVI group apparently resulting from congestive heart failure. ${ }^{7}$ Although the difference in mortality reached statistical significance, the difference in the incidence of congestive heart failure did not $^{7}$ and others have attributed this difference to underlying structural heart disease rather than to ventricular pacing itself. ${ }^{8}$ The mode of pacing (VVI) predicted the development of chronic atrial fibrillation, ${ }^{59}$ although much less strongly than did a history of paroxysmal atrial fibrillation and the use of antiarrhythmic drugs. ${ }^{5}$ Sutton and Bourgeois have reviewed 24 studies of 4111 patients with sick sinus syndrome, and have demonstrated that the mean (SD) incidence of $\mathrm{AF}$ is $1.7(1.4) \%$ in those atrially paced, compared with $8.3(3.9) \%$ in VVI paced patients. ${ }^{10}$ Mortality was also significantly less, $3.6(1 \cdot 8) \%$ v 6.4 $(2 \cdot 8) \%$ per year. $^{10}$

These retrospective studies have suggested that DDD or AAI pacing is preferable for patients with sick sinus syndrome because of the reduced incidence of atrial fibrillation, stroke, and death. They are however open to the criticism of bias, and indeed Lamas et al produced evi- dence that patients treated with ventricular pacing were older, sicker, and poorer. ${ }^{11}$ Prospective randomised trials are needed to clarify the potential benefits of AAI or DDD pacing in these patients.

Andersen et al have conducted such a trial and have demonstrated that the incidence of atrial fibrillation is less in the group allocated to atrial pacing. ${ }^{12}$ This trial confirmed the reduction in atrial fibrillation and stroke, ${ }^{12}$ but was underpowered to show a difference in mortality. ${ }^{13}$ Other randomised trials in progress are also underpowered to detect mortality difference. ${ }^{13}$ Despite this perceived lack of power, longer follow up in the Danish study has now both confirmed the benefit of atrial based pacing in terms of reduction in atrial fibrillation and stroke, and demonstrated reduced mortality. ${ }^{14}$

Design of such a prospective randomised trial is difficult: the population is elderly with a short life expectation, and prolongation of life is not necessarily the main aim. Not being elderly may alter the perception of mortality as an endpoint, but it seems that quality of life rather than quantity is important, and delaying or preventing heart failure and strokes, and reducing the need for anticoagulation, seem admirable goals. Quality of life in pacemaker recipients has been assessed by Linde, ${ }^{15}$ and two protocols have been specifically adapted for pacemaker patients. ${ }^{1617}$

\section{Systematic trial of pacing to prevent atrial fibrillation (STOP-AF) \\ DESIGN}

The Systematic trial of pacing to prevent atrial fibrillation (STOP-AF) has been designed to assess whether the use of atrially based pacing reduces the incidence of both established (or chronic) and paroxysmal atrial fibrillation. It is a multicentre prospective randomised sequential trial, and is recruiting patients from three centres in the United Kingdom and three in mainland Europe. Patients are 18 years or older and have sick sinus syndrome with or without antecedent atrial arrhythmias. Patients with class IV heart failure, rheumatic mitral valve disease, untreated thyroid disease, atrial fibrillation, previous pacemaker, terminal illness or a transplanted heart will be excluded.

\section{BASELINE ASSESSMENT}

Initial patient assessment includes assessment of cardiac function, atrial arrhythmias, previous embolism, and drug therapy. A detailed assessment of chronotropic competence will be made-those with chronotropic incompetence will be randomised in an arm that allows rate responsiveness.

\section{IMPLANT PROCEDURE}

Implantation of the dual chamber pacemaker will use the standard technique at each centre. Additional measurements of VA conduction, sinus node function, and AV Wenckebach point will be made at the time of implantation. 
PACEMAKER PROGRAMMING

The pacemaker will be programmed at implantation to the randomised mode. De facto VVI mode will be achieved by programming VDD with an AV delay of $300 \mathrm{~ms}$. (This allows atrial sensing, which will not affect pacing, but does allow the pacemaker to record atrial arrhythmias through its counters.) DDD pacing will be achieved in the usual way, and de facto AAI is permitted if desired in those with intact $\mathrm{AV}$ nodal conduction, by programming an AV delay of $300 \mathrm{~ms}$. Those with chronotropic incompetence will be randomised separately, with rate responsiveness.

\section{FOLLOW UP AND OUTCOME MEASURES}

Follow up will include regular assessment of pacemaker function, clinical events, arrhythmias, sinus node function, and exercise capacity. The primary endpoint is established atrial fibrillation. Secondary endpoints include congestive heart failure, pacemaker syndrome, change of mode because of lead problems, and death.

\section{ANALYSIS}

The trial will be analysed according to sequential trial methodology. ${ }^{18}$ This allows greater power to limit the sample size. It is anticipated assuming a middle ground (that atrial fibrillation will develop in $10 \%$ of those paced VVI and in $2 \%$ of those paced atrially) that a sample size of 350 will be required. The trial design however allows the sample size to be adjusted as appropriate during recruitment. This is a design commonly used in trials of cancer chemotherapy ${ }^{18}$ but not in cardiology. It has recently been used in the MADIT trial (of implanted defibrillators in postmyocardial infarction survivors at risk of sudden death) ${ }^{19}$ and has been criticised because of its economy of subjects. ${ }^{20}$

\section{SUBSTUDIES}

A detailed quality of life study will be conducted, as will a cost benefit analysis. Serial study of chronotropic competence and sinus node function will be performed, and the predictors of the development of atrial fibrillation in this patient population will be assessed.

\section{INITIAL EXPERIENCE}

So far almost 100 patients have been recruited, and both primary and secondary endpoints have been reached. No analysis of the data has yet been undertaken.

Similar trials are in progress in North America, and we await their results, and the details of the long term follow up of the Danish trial, with interest. They will clarify the type of pacemaker required in patients with sick sinus syndrome, and will provide the evidence on which to base guidelines and recommendations.
RGC is the principal investigator of STOP-AF, JMM is a co-investigator. STOP-AF is supported in part by Guidant. Substudies are supported by the British Heart Foundation.

RICHARD G CHARIES

Cardiothoracic Centre,

Liverpool NHS Trust

Thomas Drive, Liverpool, UK

Regional Cardiothoracic Centre,

JANET M MCCOMB

Freeman Hospital

Newcastle Upon Tyne, UK

Laslett EE. Syncopal attacks, associated with prolonged arrest of the whole heart. Ouart $\mathcal{7}$ Med 1909;2:347-55.

Watt AH. Sick sinus syndrome: an adenosine-mediated disease. Lancet 1985;i:786-8.

3 Centurion OA, Isomoto S, Shimuzu A, Konoe A, Kaibara M, Hano O, et al. Supernormal atrial conduction and its relation to atrial vulnerability and atrial fibrillation in patients with sick sinus syndrome and paroxysmal atrial fibrillation. Am Heart $\mathcal{F} 1994 ; 128: 88-95$.

4 Langenfield H, Grimm W, Maisch B, Kochsiek K. Atrial fibrillation and embolic complications in paced patients. $P A C E$ 1988;11:1667-72.

5 Sgarbossa EB, Pinski SL, Maloney JD, Simmons TW, Wilkoff BL, Castle LW, et al. Chronic atrial fibrillation and stroke in paced patients with sick sinus syndrome. Relevance of clinical characteristics and pacing modalities. Circulation 1993;88:1045-53.

6 Rosenqvist M, Brandt J, Schuller H. Atrial versus ventricular pacing in sinus node disease: a treatment comparison study. Am Heart $\mathcal{F} 1986$ 111:292-7.

7 Rosenqvist M, Brandt J, Schuller $\mathrm{H}$. Long-term pacing in sinus node disease: effects of stimulation mode on cardiovascular morbidity and mortality. Am Heart ₹ 1988;116:16-22.

8 Sgarbossa EB, Pinski SL, Trohman RG, Castle LW, Maloney JD. Single chamber ventricular pacing is not associated with worsening heart failure in sick sinus syndrome. Am $¥$ Cardiol 1994;73:693-7.

9 Hesselson AB, Parsonnet V, Bernstein AD, Bonavita GJ. Deleterious effects of long term single chamber ventricular pacing in patients with sick sinus syndrome: the hidden benefits of dual chamber pacing. $¥ \mathrm{Am}$ Coll Cardiol 1992;19:1542-9.

10 Sutton R, Bourgeois I. Cost benefit analysis of single and dual chamber pacing for sick sinus syndrome and atrioventricular block. Eur Heart $\mathcal{f}$ 1996;17:574-82.

11 Lamas GA, Pashos CL, Normand SLT, McNeil B. Permanent pacemaker selection in the elderly and subsequent survival in elderly Medicare pacemaker recipients. Circulation 1995;91:1063-9.

2 Andersen HR, Thuesen L, Bagger JP, Vesterlund T, Bloch Thomsen PE Prospective randomised trial of atrial versus ventricular pacing in sick sinus syndrome. Lancet 1994;344:1523-8.

13 Lamas GA. Pacemaker mode selection and survival: a plea to apply the principles of evidence-based medicine to cardiac pacing practice. Heart 1997;78:218-20.

14 Neilsen JC, Pedersen AK, Mortensen PT, Thuesen L, Vesterlund T, Bloch Thomsen PE, et al. Atrial versus ventricular pacing in patients with sick sinus syndrome. Long term follow up in a prospective randomised trial of 225 consecutive patients [abstract]. $P A C E$ 1997;20 (part II):1458.

15 Linde C. How to evaluate quality of life in pacemaker patients: problems and pitfalls. $P A C E$ 1996;19:391-7.

16 Oto MA, Muderrisoglu H, Ozin MB, et al. Quality of life in patients with rate responsive pacemakers: a randomized cross over study. PACE 1991;14: $800-6$

17 Linde-Edelstam C, Nordlander R, Unden A-L, Orth-Gomer K, Ryden L. Quality of life in patients treated with atrioventricular synchronous pacing compared to rate modulated ventricular pacing: a long term double blind crossover study. PACE 1992;15(part I):1467-76.

18 Whitehead J. Interim analyses and stopping rules in cancer clinical trials. $\mathrm{Br}$ f Cancer 1993;68:1179-85.

19 Moss AJ, Hall WJ, Cannom DS, Daubert JP, Higgins SL, Klein H, et al, for the Multicenter Automatic Defibrillator Trial investigators. Improved survival with an implanted defibrillator in patients with coronary disease at high risk of ventricular arrhythmias. N Engl f Med 1996;335:1933-40.

20 Freidman PL, Stevenson WG. Unsustained ventricular tachycardia-to treat or not to treat [editorial]. N Engl f Med 1996;335:1984-5.

21 Toff WD, Skehan JD, de Bono DP, Camm AJ. The United Kingdom Pacing and cardiovascular events (UKPACE) trial. Heart 1997;78: $221-3$ 